\title{
CARACTERÍSTICAS DA CARCAÇA, COMPONENTES NÃO- CARCAÇA E DOS CORTES COMERCIAIS DE CORDEIROS ROMNEY MARSH ABATIDOS EM DIFERENTES IDADES
}

\footnotetext{
José Carlos da Silveira Osório ${ }^{1}$, Maria Teresa Moreira Osório ${ }^{1}$, Orli Rogério Cordova de Sousa², Otoniel Geter Lauz Ferreira ${ }^{1}$, Fernando Amarilho Silveira ${ }^{3}$, Pâmela Peres Farias ${ }^{3}$, Pablo Tavares Costa $^{3}$, Luiza Padilha Nunes ${ }^{3}$

${ }^{1}$ Departamento de Zootecnia - Faculdade de Agronomia Eliseu Maciel - Universidade Federal de Pelotas. ${ }^{2}$ Empresa de Pesquisa Agropecuária e Extensão Rural de Santa Catarina. ${ }^{3}$ Programa de Pós-Graduação em Zootecnia - Faculdade de Agronomia Eliseu Maciel - Universidade Federal de Pelotas.
}

RESUMO: O objetivo do trabalho foi avaliar o rendimento e a qualidade da carcaça, a partir da composição regional e tecidual da paleta e da perna, de cordeiros Romney Marsh abatidos em diferentes idades. O experimento foi conduzido em uma propriedade particular do município de Campos Novos, região Meio Oeste de Santa Catarina, utilizando-se 38 cordeiros da raça Romney Marsh, mantidos sob sistema de manejo tradicional da propriedade. Os animais foram abatidos com 90 e 180 dias de idade, sendo mensurado o ganho de peso médio diário, rendimento de carcaça, percentual dos cortes paleta, perna, costilhar e pescoço, percentual dos componentes da não carcaça (pele, vísceras, cabeça, patas e pulmão) além da composição tecidual (percentagem de osso, músculo e gordura) da paleta e da perna. Animais abatidos aos 90 dias de idade apresentaram maior rendimento de carcaça, mas não diferiram dos abatidos aos 180 dias quanto ao percentual de pescoço, costilhar, paleta e perna. Para os componentes teciduais, na paleta o percentual de osso não diferiu entre as idades de abate, todavia o percentual de músculo foi maior nos animais abatidos com 90 dias e o de gordura nos abatidos aos de 180 dias. Na perna, os percentuais de osso, músculo e gordura não diferiram entre as diferentes idades de abate. Todos os componentes não carcaça diferiram entre as idades de abate. Cordeiros da raça Romney Marsh apresentam maiores rendimentos de carcaça quando abatidos aos 90 dias de idade. $O$ percentual dos cortes pescoço, costilhar, paleta e perna não diferem para animais abatidos aos $90 \mathrm{e}$ 180 dias de vida. Animais abatidos aos 90 dias apresentam maiores percentuais de músculo, e aos 180 dias, maiores percentuais de gordura, na paleta. Na perna, os percentuais de osso, músculo e gordura não diferem entre as idades de abate.

Palavras-chave: composição regional, composição tecidual, rendimento de carcaça 


\section{CARCASS TRAITS, NON-CARCASS COMPONENTS AND COMMERCIAL CUTTING OF ROMNEY MARSH LAMBS SLAUGHTERED IN DIFFERENT AGES}

ABSTRACT: The objective of this study was to evaluate carcass yield and quality, from the regional and tissue composition of the palette and leg, of Romney Marsh lambs slaughtered at different ages. The experiment was conducted in a private property of the municipality of Campos Novos. Half-West region of Santa Catarina, using 38 Romney Marsh lambs, kept under the traditional management system of the property. The animals were slaughtered with 90 and 180 days of age, being measured the average daily weight gain, carcass yield, percentage of the cuts palette, leg, ribs and neck, percentage of the components of the non-carcass (skin, viscera, head, paws and Lung) In addition to the tissue composition (percentage of bone, muscle and fat) of the palette and leg. Animals slaughtered at 90 days of age presented higher carcass yield, but not differing from those slaughtered at 180 days in relation to the percentage of neck, ribs, palette and leg. For The tissue components, in the palette the percentage of bone did not differ between the slaughter ages, however the percentage of muscle was higher in the animals slaughtered with 90 days and the fat in the slaughtered at 180 days. In the leg, the percentages of bone, muscle and fat did not differ between the different slaughter ages. All non-carcass components differed between slaughter ages. Romney Marsh lambs present higher carcass yields when slaughtered at 90 days of age. The percentage of neck, ribs, palette and leg cuts do not differ for animals slaughtered at 90 and 180 days of life. Animals slaughtered at 90 days presented higher percentages of muscle, and at 180 days, higher percentages of fat, in the palette. In the leg, the percentages of bone, muscle and fat do not differ between the slaughter ages.

Keywords: regional composition, tissue composition, carcass yield

\section{INTRODUÇÃO}

Entre as décadas de 1980 e 1990 a ovinocultura brasileira sofreu uma remodelagem, na qual, devido à crise da lã, mudou de foco, direcionando-se para a produção de carne (VIANA, 2008). Deste modo, pós-crise da lã, os rebanhos diminuíram, e os ovinocultores, para se manterem na atividade, iniciaram um novo ciclo de investimentos idealizados pela demanda do produto carne. Com isso se criou uma cadeia ovina complexa, em que o animal é selecionado, abatido e comercializado, juntamente com a exigência do consumidor, que primordialmente buscava um "pedaço" de carne e hoje exige um alimento organicamente benéfico (OSÓRIO et al., 2012a). 
A diminuição da pobreza em países em desenvolvimento, com consequente aumento do poder aquisitivo, torna a carne um alimento cada vez mais presente no prato dos consumidores, principalmente por ser um nutriente essencial na alimentação diária (ALVES et al., 2014). As carnes bovina, suína e de frango já estão presentes na mesa do brasileiro, todavia a carne ovina precisa conquistar seu espaço na preferência do consumidor; aproximadamente $12 \%$ de consumidores do País, nunca sequer experimentaram a proteína oriunda de ovelhas, carneiros ou cordeiros (EMBRAPA, 2018). Todavia, apesar do baixo consumo, a carne ovina é bem apreciada em grandes centros urbanos, porém com demanda de um produto de qualidade, exigindo diferenciação, principalmente, entre carne de cordeiro e de carneiro (PANEA et al., 2013). A carne de cordeiro é uma excelente fonte de proteínas, contendo aminoácidos essenciais, baixa concentração de lipídios e de gordura saturada (ALVES et al., 2014). Segundo Arruda et al. (2012), é ainda caracterizada por ser macia e rosada, ter textura lisa, consistência firme e gordura rica em ácidos graxos monoinsaturados que ajudam a reduzir os níveis de LDL no sangue.

A qualidade da carne sofre alterações consideráveis com a idade, decorrente de mudanças na composição e nas características metabólicas dos músculos (SILVA SOBRINHO et al., 2008). O aumento da idade de abate ainda contribui para a deposição de gordura e músculo na carcaça (TODARO et al., 2004).

A idade do animal está intimamente relacionada com o peso corporal, o estado de engorduramento e com a composição regional e tecidual. Com o aumento da idade, os pesos de abate e da carcaça aumentam, a porcentagem de músculo diminui, a de gordura aumenta e a de osso aumenta levemente (OSÓRIO et al., 2000). Assim, para cada raça existe um peso ótimo de abate, onde a proporção de músculo é máxima, a de osso é mínima e a de gordura é suficiente para manter as propriedades organolépticas e de conservação (OSÓRIO et al., 1998). Sendo o peso ótimo de abate aquele obtido em menor período de tempo, com menor custo e com máxima qualidade do produto, a antecipação da terminação, e consequente abate, traz consigo vantagens para o produtor e o consumidor. Surge assim, diante disso, a necessidade de se determinar a idade de abate que proporcione adequado 
rendimento de carcaça aliado a características que promovam a melhor apreciação do produto carne pelo consumidor. Neste sentido, o presente trabalho objetivou avaliar o rendimento e a qualidade da carcaça de cordeiros da raça Romney Marsh abatidos em duas idades.

\section{MATERIAL E MÉTODOS}

A condução deste estudo foi aprovada pela Comissão de Ética em Experimentação Animal, da Universidade Federal de Pelotas, RS, sob o № 6730. O experimento foi realizado em uma propriedade particular localizada no município de Campos Novos $\left(27^{\circ} 24^{\prime \prime S}\right.$ e $51^{\circ} 12$ "O), região Meio Oeste de Santa Catarina. A temperatura média anual é de $19,8^{\circ} \mathrm{C}$, com média mínima de $17,2^{\circ} \mathrm{C}$ e média máxima de $22,4^{\circ} \mathrm{C}$ e precipitação média anual de $2.127,7 \mathrm{~mm}$. O registro das principais variáveis climatológicas ocorridas durante o período experimental encontram-se na Tabela 1. A propriedade, localizada a 930 metros de altitude, possui solo com topografia suavemente ondulada variando de Argisolo a Latossolo Roxo distrófico e Latossolo Húmico distrófico.

Tabela 1 - Registros das principais variáveis climatológicas ocorridas durante o período experimental.

\begin{tabular}{|c|c|c|c|c|c|c|c|}
\hline Mês & $\begin{array}{l}\text { Temperatura } \\
\text { Médias }\left({ }^{\circ} \mathrm{C}\right)\end{array}$ & $\begin{array}{l}\text { Dias com } \\
\text { chuva }\left(n^{\circ}\right)\end{array}$ & $\begin{array}{c}\text { Geadas } \\
\qquad\left(\mathrm{n}^{\circ}\right)\end{array}$ & $\begin{array}{c}\text { Precipitação } \\
\text { pluviométrica (mm) }\end{array}$ & $\begin{array}{c}\text { Evaporação } \\
(\mathrm{mm})\end{array}$ & $\begin{array}{l}\text { Insolação } \\
\text { (h) }\end{array}$ & $\begin{array}{c}\text { Umidade } \\
\text { Relativa do } \mathrm{Ar} \\
(\%)\end{array}$ \\
\hline Jan & 21,2 & 14 & - & 166,5 & 3,3 & 7,9 & 72,3 \\
\hline Fev & 22,2 & 21 & - & 118,4 & 2,9 & 5,9 & 78,5 \\
\hline Mar & 20,8 & 21 & - & 175,1 & 2,4 & 5,4 & 80,8 \\
\hline Abr & 17 & 11 & - & 76,3 & 2,3 & 5,1 & 80,8 \\
\hline Mai & 14,8 & 16 & 2 & 448,6 & 2,1 & 4 & 83,3 \\
\hline Jun & 15,3 & 10 & 1 & 236,9 & 2,8 & 4,5 & 80,3 \\
\hline Jul & 11,1 & 12 & 5 & 200,4 & 2,6 & 4,3 & 81,6 \\
\hline Ago & 12 & 13 & 3 & 227,1 & 2,5 & 4,7 & 80,2 \\
\hline Set & 15,3 & 13 & - & 230,7 & 3,1 & 5,9 & 72,6 \\
\hline Out & 17,8 & 13 & - & 84,5 & 3,3 & 5,9 & 70,3 \\
\hline Nov & 18,3 & 10 & 1 & 221,5 & 3,6 & 7,4 & 67,1 \\
\hline Dez & 21,7 & 11 & - & 74,9 & 4,4 & 8,6 & 67,3 \\
\hline Jan & 21,7 & 9 & - & 76,1 & 2,6 & 6,6 & 85,7 \\
\hline
\end{tabular}

Fonte: Estação Meteorológica 8o DISME EPAGRI - Campos Novos - SC. 
Foram utilizados 38 cordeiros machos, não castrados, da raça Romney Marsh, que após serem identificados, foram pesados ao nascimento (agosto) e a cada 28 dias até o término do período experimental. Além disso, foram vermifugados e vacinados contra carbúnculo sintomático, sendo desmamados com aproximadamente 90 dias de idade. Os animais eram mantidos sob sistema de manejo tradicional da região, tendo como base alimentar do nascimento aos 120 dias de idade (15 de novembro), pastagem de azevém anual (Lolium multiflorum Lam.) com lotação média de 08 cabeças por hectare. Dos 120 aos 150 dias de idade (15 de dezembro) pastagem nativa (06 cabeças/ha), e dos 150 aos 180 dias de idade (15 de janeiro), pastagem cultivada de milheto (Penisetum americanum), com lotação média de 08 cabeças/ha, sempre sob método de lotação rotacionada e disponibilidade de forragem que não restringisse 0 consumo pelos animais (RATTRAY et al., 1987).

Os abates foram realizados aos 90 e 180 dias de idade. Para determinar os primeiros 19 animais a serem abatidos, os 38 cordeiros foram divididos em subgrupos com diferentes intervalos de peso. A partir da diferença entre o cordeiro mais pesado $(28 \mathrm{Kg})$ e o mais leve $(16,5 \mathrm{Kg})$ foram formados os seguintes grupos: de 16 a $20 \mathrm{Kg}$ com 9 animais; 20,1 a 24,0 Kg com 17 animais e; 24,1 a 28,0 kg com 12 animais. A definição dos animais para o primeiro abate (90 dias de idade) foi realizada ao acaso, sorteando-se a metade de cada subgrupo. Os animais restantes foram abatidos aos 180 dias de idade. Ambos os abates foram realizados de acordo com os procedimentos que caracterizam abate humanitário (MONTEIRO JÚNIOR, 2000). Simultaneamente ao abate dos primeiros animais, os cordeiros a serem abatidos aos 180 dias foram desmamados.

Foram avaliadas as seguintes variáveis in vivo: peso ao nascer, peso corporal ao abate e ganho de peso médio diário (peso corporal ao abate - peso ao nascer/no de dias entre o nascimento e o abate). No pós-abate foram avaliados, conforme Selaive-Villarroel; Osório (2014), o rendimento no frigorífico (relação percentual entre o peso da carcaça quente e o peso corporal pré-abate pós-jejum de 12 horas); a relação percentual entre o peso dos cortes paleta, perna, costilhar e pescoço e o 
peso da carcaça fria; a relação percentual entre o peso dos componentes da não carcaça (pele, vísceras, cabeça, patas e pulmão) e o peso corporal; e a composição tecidual (relação percentual entre o peso de osso, músculo e gordura e o peso do corte) da paleta e da perna. Para isso, as meias-carcaças esquerdas foram separadas nos cortes paleta, costela, pernil e pescoço. Cada um destes foi pesado individualmente (em $\mathrm{kg}$ ), identificado e armazenado em embalagens individuais, sendo acondicionados em freezer a temperatura de $-18^{\circ}$ C. Após o descongelamento foi realizada a dissecação dos cortes com auxílio de faca, bisturi e pinça, sendo determinada a composição tecidual de gordura total (gorduras subcutânea e intermuscular), músculos e ossos. Os componentes teciduais foram pesados individualmente para serem expressos em relação ao peso total dos cortes.

Utilizou-se o delineamento experimental completamente casualizado, sendo a análise estatística realizada pelo método dos quadrados mínimos, baseada no seguinte modelo: $Y i j=\mu+S i+\varepsilon i j$, em que: Yij = variável resposta, $\mu=$ média geral, Sij = efeito de idade ao abate, i ( 1 = 90 dias e 2 = 180 dias $)$ e $\varepsilon i j=$ erro experimental.

\section{RESULTADOS}

Não foram verificadas diferenças significativas $(P>0,05)$ entre 0 peso ao nascer dos animais abatidos nas diferentes idades (Tabela 2), não havendo assim influencia desta variável sobre os resultados obtidos no abate. Também não foi encontrada diferença significativa no ganho de peso médio diário (GMD) do nascimento aos 90 dias de idade em nenhum dos grupos de abate estudados, no entanto, a partir desta idade, os animais a serem abatidos aos 180 dias reduziram seu ganho em aproximadamente $50 \%$ quando comparados àqueles abatidos aos 90 dias (Tabela 2). 
Tabela 2 - Médias e desvios-padrão do peso corporal ao nascer, ganho médio diário (GMD) e do peso corporal ao abate de cordeiros Romney Marsh abatidos com diferentes idades.

\begin{tabular}{lcccc}
\hline & \multicolumn{2}{c}{ Idade de abate } & \multirow{2}{*}{ CV(\%) } & \multirow{2}{*}{ Pr>F } \\
\cline { 2 - 3 } & $\mathbf{9 0}$ dias & $\mathbf{1 8 0}$ dias & & \\
\hline Peso ao nascer $(\mathbf{K g})$ & $4,72 \pm 0,90$ & $4,47 \pm 1,16$ & 22,74 & 0,4577 \\
GMD 0-90 $(\mathbf{K g})$ & $0,197 \pm 0,03$ & $0,198 \pm 0,02 \mathrm{a}^{*}$ & 14,73 & 0,9103 \\
GMD 90-180 $(\mathbf{K g})$ & - & $0,104 \pm 0,01 \mathrm{~b}^{*}$ & - & - \\
Peso ao abate $(\mathrm{Kg})$ & $22,52 \pm 3,03$ & $31,44 \pm 3,67$ & 12,48 & $<0,0001$ \\
\hline
\end{tabular}

*Letras diferentes na coluna indica a ocorrência de diferença significativa $(\mathrm{P}<0,0001 ; \mathrm{CV}=14,98 \%)$.

Animais abatidos aos 90 dias apresentaram menor peso ao abate (Tabela 2), contudo, maior rendimento quando comparados aos abatidos com 180 dias de idade (Tabela 3).

Não foi encontrada diferença significativa $(P>0,05)$ para nenhum dos componentes da carcaça, a saber, pescoço, costilhar, paleta e perna (Tabela 3).

Tabela 3 - Média e desvio-padrão dos componentes da carcaça em percentual e peso absoluto entre parênteses de cordeiros Romney Marsh abatidos com diferentes idades.

\begin{tabular}{|c|c|c|c|c|}
\hline \multirow{2}{*}{ Componente da carcaça } & \multicolumn{2}{|c|}{ Idade de abate } & \multirow{2}{*}{ CV(\%) } & \multirow{2}{*}{$\mathrm{Pr}>\mathrm{F}$} \\
\hline & 90 dias & 180 dias & & \\
\hline Rendimento de carcaça (\%) & $\begin{array}{c}48,53 \pm 4,62 \\
(9,88 \mathrm{~kg})\end{array}$ & $\begin{array}{c}41,44 \pm 2,41 \\
(11,86 \mathrm{~kg})\end{array}$ & 8,15 & 0,00003 \\
\hline Pescoço (\%) & $\begin{array}{c}7,49 \pm 0,88 \\
(0,37 \mathrm{~kg})\end{array}$ & $\begin{array}{c}8,14 \pm 1,96 \\
(0,47 \mathrm{~kg})\end{array}$ & 19,13 & 0,50876 \\
\hline Costilhar (\%) & $\begin{array}{c}36,97 \pm 1,46 \\
(1,78 \mathrm{~kg})\end{array}$ & $\begin{array}{c}35,69 \pm 3,46 \\
(2,07 \mathrm{~kg})\end{array}$ & 7,32 & 0,14214 \\
\hline Paleta (\%) & $\begin{array}{c}20,02 \pm 0,85 \\
(0,96 \mathrm{~kg})\end{array}$ & $\begin{array}{c}20,74 \pm 1,68 \\
(1,19 \mathrm{~kg})\end{array}$ & 6,55 & 0,09808 \\
\hline Perna (\%) & $\begin{array}{c}33,45 \pm 1,23 \\
(1,9 \mathrm{~kg})\end{array}$ & $\begin{array}{c}33,24 \pm 1,28 \\
(1,92 \mathrm{~kg})\end{array}$ & 4,67 & 0,69583 \\
\hline
\end{tabular}

$\mathrm{Na}$ fração não carcaça, verificou-se superioridade no percentual de pele e vísceras nos animais abatidos aos 180 dias de idade, enquanto os percentuais de cabeça, patas e pulmão nos animais abatidos aos 90 dias de idade (Tabela 4). 
Tabela 4 - Média e desvio-padrão dos componentes da fração não carcaça em percentual de cordeiros Romney Marsh abatidos com diferentes idades.

\begin{tabular}{|c|c|c|c|c|}
\hline & \multicolumn{2}{|c|}{ Idade de abate } & \multirow{2}{*}{$\mathrm{CV}(\%)$} & \multirow{2}{*}{$\operatorname{Pr}>\mathrm{F}$} \\
\hline & 90 dias & 180 dias & & \\
\hline Pele (\%) & $14,20 \pm 1,59$ & $18,18 \pm 2,30$ & 12,22 & 0,00001 \\
\hline Vísceras (\%) & $17,85 \pm 2,46$ & $23,42 \pm 0,41$ & 11,72 & 0,00001 \\
\hline Cabeça (\%) & $6,45 \pm 0,70$ & $4,28 \pm 0,41$ & 10,72 & 0,00001 \\
\hline Patas (\%) & $3,20 \pm 0,48$ & $2,68 \pm 0,23$ & 12,80 & 0,00032 \\
\hline Pulmão (\%) & $2,08 \pm 0,28$ & $1,83 \pm 0,26$ & 14,16 & 0,00736 \\
\hline
\end{tabular}

Não foi encontrada diferença $(P>0,05)$ para o percentual de ossos na paleta e de todos componentes teciduais na perna. Os animais abatidos aos 90 dias de idade apresentaram maiores percentuais de músculo na paleta, entretanto o percentual de gordura nesse corte foi superior para os animais abatidos aos 180 dias (Tabela 5).

Tabela 5 - Média e desvio-padrão dos componentes teciduais da paleta e da perna em percentual e peso entre parênteses de cordeiros Romney Marsh abatidos com diferentes idades.

\begin{tabular}{|c|c|c|c|c|}
\hline \multirow{2}{*}{ Componente Tecidual } & \multicolumn{2}{|c|}{ Idade de abate } & \multirow{2}{*}{$\mathrm{CV}(\%)$} & \multirow{2}{*}{$\mathrm{Pr}>\mathrm{F}$} \\
\hline & 90 dias & 180 dias & & \\
\hline \multicolumn{5}{|l|}{ Paleta } \\
\hline & $22,88 \pm 1,91$ & $21,84 \pm 1,72$ & & \\
\hline Osso (\%) & $(0,21 \mathrm{Kg})$ & $(0,26 \mathrm{~kg})$ & 8,15 & 0,08354 \\
\hline & $69,09 \pm 3,97$ & $65,75 \pm 4,50$ & & \\
\hline Músculo (\%) & $(0,66$ kg) & $(0,74$ kg) & 6,30 & 0,01941 \\
\hline Gordura (\%) & $\begin{array}{l}8,04 \pm 5,15 \\
(0,08 \mathrm{~kg})\end{array}$ & $\begin{array}{c}12,40 \pm 5,48 \\
(0,15 \mathrm{~kg})\end{array}$ & 52,04 & 0,01525 \\
\hline Perna & & & & \\
\hline Osso (\%) & $\begin{array}{r}27,98 \pm 1,32 \\
(0,44 \mathrm{~kg})\end{array}$ & $\begin{array}{c}28,49 \pm 2,18 \\
(0,54 \mathrm{~kg})\end{array}$ & 6,38 & 0,60345 \\
\hline
\end{tabular}




$\begin{array}{lcccr}\text { Músculo (\%) } & 67,79 \pm 1,59 & 66,67 \pm 2,31 & 2,95 & 0,08428 \\ & (1,08 \mathrm{~kg}) & (1,27 \mathrm{~kg}) & & \\ \text { Gordura (\%) } & 4,17 \pm 1,59 & 4,79 \pm 2,31 & & \\ & (0,07 \mathrm{~kg}) & (0,09 \mathrm{~kg}) & 51,34 & 0,58580\end{array}$

\section{DISCUSSÃO}

O menor desempenho verificado a partir dos 90 dias de idade foi decorrente do estresse sofrido pelos animais por ocasião de seu desmame, que se deu aos 90 dias, e das alterações de sua alimentação até o momento do abate. Visto que, até os 90 dias de idade média, todos os animais, além de estarem mamando, se alimentaram de azevém anual em estágio vegetativo, período em que essa forrageira expressa sua suprema qualidade bromatológica (COSTA et al., 2018), proporcionando elevados desempenhos. Os abatidos aos 180 dias, agora desmamados, passaram a se alimentar de azevém em estágio avançado de desenvolvimento, de pastagem nativa e de pastagem cultivada de milheto, configurando uma dieta de menor qualidade (MOTTA et al., 2016; COSTA et al., 2018). Como resultado, embora sob condições climáticas favoráveis (Tabela 1) apresentaram GMD de somente 0,104 kg entre o desmame (90 dias) e o abate. Todavia, deve-se ressaltar que apesar do menor GMD, em função do maior período proporcionado para seu crescimento, os animais deste tratamento apresentaram peso final superior àqueles abatidos aos 90 dias (Tabela 2). Esse resultado é coerente com a observação de Ramsey et al. (1994), os quais afirmam que o potencial de crescimento dos cordeiros nas primeiras semanas de vida é determinado, dentre outros fatores, pela produção de leite da ovelha, sendo que, conforme Folman et al. (1966), o desmame causa decréscimo no desempenho. Do mesmo modo, Müller et al. (2006) encontraram para cordeiros cruza Texel x lle de France maiores ganhos do nascimento ao desmame quando comparado ao período entre o desmame e o abate. Os resultados também estão de acordo com os obtidos 
por Bueno et al. (2000), que trabalhando com três idades de abate (90, 130 e 170 dias) encontraram maiores valores de peso final nos abatidos mais velhos (170 dias).

O maior rendimento de carcaça dos animais abatidos aos 90 dias se deve ao menor percentual dos componentes da não carcaça pele e vísceras, os quais foram superiores nos cordeiros abatidos aos 180 dias em 3,98 e 5,57\%, respectivamente (Tabela 4). Segundo Silva e Pires (2000), maiores rendimentos de carcaça ovina são esperados para animais jovens, uma vez que, com o avanço da idade, ocorre aumento do trato gastrintestinal, o qual contribui para a redução do percentual de carcaça em relação ao peso de abate. Considerando-se que o rendimento de carcaça expressa a produção de carne, verifica-se que os cordeiros abatidos aos 90 dias, foram mais eficientes em relação aos abatidos aos 180 dias de idade, mesmo apresentando menores peso de carcaça. Bueno et al. (2000) encontraram valores que contrariam os resultados deste trabalho, em que ovinos da raça Suffolk apresentaram maiores rendimentos de carcaças ao avançar da idade. Todavia essa divergência é explicada por Osório et al. (2004), já que, segundo os autores, ovinos de raças com aptidão carniceira, como a Suffolk, por possuírem menor precocidade na deposição de gordura, apresentam maiores proporções de musculo em relação as outras frações teciduais, proporcionando maior rendimento quando comparadas a raças de duplo propósito, no caso da Romney Marsh.

O maior percentual de pele encontrado nos animais abatidos aos 180 dias de idade (Tabela 4) atribui-se a maior idade e peso vivo ao abate apresentado pelos mesmos. Sendo estes mais pesados e mais velhos, possuíam maior área corporal e, consequentemente, maior extensão de pele, além de lã de maior comprimento. Neste sentido, Bueno et al. (2000) também encontraram em ovinos da raça Suffolk aumento no percentual de pele com o aumento da idade dos animais.

Quanto as vísceras, o fato dos animais abatidos aos 180 dias terem se alimentado de forragens mais fibrosas provavelmente proporcionou o maior desenvolvimento das mesmas. Várias são as bibliografias que relacionam baixa qualidade do alimento disponível com maior peso de vísceras de ovinos (MOTTA et al., 2016). De acordo com Carvalho et al. (2003), o fornecimento de alimento sólido 
promove aumento da capacidade ruminal e do tecido muscular das paredes do órgão. Assim, Carvalho et al. (2007) ao avaliarem diferentes sistemas de terminação de cordeiros observaram menor desempenho e maior proporção de vísceras naqueles terminados em pastagem, o alimento mais fibroso utilizado no experimento.

Para explicar a superioridade no percentual de cabeça e patas nos animais abatidos aos 90 dias de idade, Lawrie (2005) descreve que as ondas de crescimento e desenvolvimento animal, são disto-proximais e anteroposteriores, logo quanto mais jovem o animal, maior será a proporção das extremidades e da região anterior. Já o maior percentual de pulmão se deve ao fato de que os órgãos vitais têm maior desenvolvimento em uma fase mais precoce da vida do animal (BERG; BUTERFILD, 1976).

O maior percentual de músculo na paleta dos animais abatidos aos 90 dias e o maior percentual de gordura na paleta nos animais abatidos aos 180 dias (Tabela 5) é explicada por Taylor (1985). Conforme o autor, o aumento da maturidade dos animais leva a aumento na proporção de gordura, diminuição na de ossos e pouca mudança na de músculos. De acordo com Osório et al. (2014b), sendo a taxa de crescimento da gordura mais rápida que a do músculo e osso, ocorre aumento progressivo da porcentagem de gordura na carcaça e redução da porcentagem de músculo e osso, à medida que o cordeiro fica mais pesado.

Jardim et al. (2007) explicam que o fato dos animais mais jovens terem maior percentual de músculo se deve a ocorrência de hipertrofia das fibras musculares acarretada pelo rápido desenvolvimento que ocorre quando as condições alimentares são favoráveis, fato que, no presente estudo, ocorreu até os 90 dias, pela oferta de leite materno e forragem de alta qualidade. Os mesmos autores trabalhando com três diferentes idades de abate, verificaram que os ovinos abatidos aos 210 dias apresentavam maiores valores para a gordura subcutânea na paleta, enquanto que os abatidos aos 120 dias apresentaram maiores pesos de gordura intramuscular na paleta e na perna, e maior peso de gordura subcutânea na perna. Os abatidos aos 360 dias de idade apresentaram pesos muito baixos de gordura subcutânea e intermuscular, tanto na paleta como na perna. Por sua vez, Silva 
Sobrinho et al. (2002) verificaram que cordeiros da raça Santa Inês abatidos aos 300 dias de idade apresentavam menor peso de gordura total na perna do que os abatidos aos 150 dias de idade.

\section{CONCLUSÕES}

Cordeiros da raça Romney Marsh apresentam maiores rendimentos de carcaça quando abatidos aos 90 dias de idade.

O percentual dos cortes pescoço, costilhar, paleta e perna não diferem para animais abatidos aos 90 e 180 dias de vida.

Animais abatidos aos 90 dias apresentam maiores percentuais de músculo, e aos 180 dias, maiores percentuais de gordura, na paleta. Na perna, os percentuais de osso, músculo e gordura não diferem entre as idades de abate.

\section{REFERÊNCIAS}

ALVES, L. G. C.; OSÓRIO, J. C. S.; FERNANDES, A. R. M.; RICARDO, H. A.; CUNHA, C. M. Produção de carne ovina com foco no consumidor. Enciclopédia Biosfera, Centro Científico Conhecer - Goiânia, v.10, n.18; p. 2399, 2014

ARRUDA, P. C. L.; PEREIRA, E. S.; PIMENTEL, P. G.; BOMFIM, M. A. D.; MIZUBUTI, I. Y.; Ribeiro, E. L. A.; FONTENELE, R. M.; REGADAS FILHO, J. G. L . Perfil de ácidos graxos no Longissimus dorsi de cordeiros Santa Inês alimentados com diferentes níveis energéticos. Semina: Ciências Agrárias, Londrina, v. 33, n. 3, p. 1229-1240, 2012. DOI: 10.5433/1679-0359.2012v33n3p1229

BERG, R. T.; BUTTERFILD, R. M. New concepts of cattle growth. New York; Sidney University, p. 240, 1976.

BUENO, M. S.; CUNHA, E. A.; SANTOS, L. E. et al. Características de Carcaça de Cordeiros Suffolk Abatidos em Diferentes Idades. Revista rasileira de zootecnia, v. 29 , n. 6 , p. 1803-1810, 2000.

CARVALHO, P. A.; SANCHEZ, L. M. B.; VIÉGAS, J.; VELHO, J. P.; JAURIS, G. C.; RODRIGUES, M. B. Desenvolvimento de estômago de bezerros holandeses desaleitados precocemente. Revista Brasileira de Zootecnia, v.32, p.1461-1468, 2003.

CARVAlHO, S.; BROCHIER, M. A.; PIVATO, J.; TEIXEIRA, R. C.; KIELING, R. Ganho de peso, características da carcaça e componentes não-carcaça de cordeiros 
da raça Texel terminados em diferentes sistemas alimentares. Ciência Rural, v.37, p.821-827, 2007

COSTA, O. A. D.; FERREIRA, O. G. L.; SILVA, J. L. S.; FLUCK, A. C.; KRONING, A. B.; OLIVEIRA, L. V.; COELHO, R. A. T.; BRONDANI, W. C. Yield, structural composition and nutritive characteristics of ryegrass cultivars used to haymaking in lowland soils. Bioscience Journal, v. 34, p. 1232-1238, 2018. http://dx.doi.org/10.14393/bj-v34n5a2018-39405

EMBRAPA PECUÁRIA SUL. Disponível em: < https://www.embrapa.br/pecuariasul/busca-de-noticias/-/noticia/34766692/pesquisa-mostra-que-12-dos-brasileirosnunca-comeram-carne-ovina>. Acesso em: 19 mar 2019.

FOLMAN, Y.; EYAL, E.; VOLCANI, R. Mother-offspring relationships in Awassi sheep. The effect of different suckling regimes and weaning age on weight gains of lambs in dairy flocks. Journal of Agriculture Science, v. 67, p. 371-376, 1966.

JARDIM, R. D.; OSÓRIO, J. C. S.; OSÓRIO, M. T. M. et al. Efeito da Idade de Abate e Castração Sobre a Composição Tecidual e Química da Paleta e da Perna de Ovinos Corriedale. Revista Brasileira de Agrociência, Pelotas, v. 13, n. 2, p. 237-242, 2007.

LAWRIE, R. A. Fatores que influenciam o crescimento e desenvolvimento dos animais de corte. In: LAWRIE, R. A. (Ed.) Ciência da carne. Porto Alegre: Artmed, p. 29-50, 2005.

MONTEIRO JÚNIOR, I.A. Avaliação das técnicas de insensibilização de ovinos abatidos na região de Botucatu. 2000. 166f. Dissertação (Mestrado em Medicina Veterinária). Faculdade de Medicina Veterinária e Zootecnia, Universidade Estadual Paulista, Botucatu, 2000.

MOTTA, J. F. ; FERREIRA, O. G. L. ; VAZ, R. Z. ; COSTA, O. A. D. ; ALONZO, L. A. G.; GONÇALVES, M.; LOPES, A. G. ; PEDRA, W. U. Desempenho produtivo e qualidade da carcaça de cordeiros avaliados em dois sistemas alimentares. Boletim de Indústria Animal (Online), v. 73, p. 15-23, 2016. DOI:http://dx.doi.org/10.17523/bia.v73n1p15

MÜLLER, L.; PIRES, C. C.; TONETTO, C. J.; et al. Efeito do desmame precoce em cordeiros cruzas lle de France $x$ Texel no desempenho e nas características da carcaça. Revista Ciência Agronômica, v.37, n.2, p. 241-245, 2006.

OSÓRIO, J. C. S.; SAÑUDO, C.; OSÓRIO, M. T. M.; SIERRA, I. Produção de carne ovina - Alternativa para o Rio Grande do Sul. Pelotas: UFPel, 166p. 1998.

OSÓRIO, J. C. S.; OLIVEIRA, N. M.; OSÓRIO, M. T. M.; PIMENTEL, M.; POUEY, J. L. Efecto de la edad al sacrificio sobre la producción de carne en corderos no 
castrados de cuatro razas. Revista Brasileira de Agrociência, v. 6, n. 2, p. 161-166, 2000.

OSÓRIO, J, C, S.; OSÓRIO, M, T, M. Lã. In: OSÓRIO, J, C, S.; OSÓRIO, M, T, M. Zootecnia de Ovinos: Raças, Lã, Morfologia, Avaliação de carcaças, Comportamento em pastejo. Pelotas : Departamento de Zootecnia / Faculdade de Agronomia Eliseu Maciel / Universidade Federal de Pelotas, , p. 123, 2004.

OSÓRIO, J. C. S.; OSÓRIO, M. T. M.; FERREIRA, O. G. L.; VARGAS JUNIOR, F. M.; FERNANDES, A. R. M.; RICARDO, H. A.; ALVES, L. G. C.; ORRICO JÚNIOR, M. A. P. Avaliação da carcaça de caprinos e ovinos. PUBVET, Londrina, v. 6, n. 23, Ed.2 09, Art.1403, 2012a.

OSÓRIO, J. C. S.; OSORIO, M. T. M.; FERNANDES, A. R. M.; VARGAS JÚNIOR, F. M. de. Produção e qualidade de carcaça ovina. In: SELAIVE-VILLARROEL, A.B.; OSORIO, J.C.S (Eds.). Produção de ovinos no Brasil. São Paulo: Roca, p.399-445. $2014 b$.

PANEA, B.; RIPOLL, G.; JOY, M. Caracterización y agrupamiento de algunos tipos comerciales de cordero por su perfil sensorial. ITEA - Información Técnica Económica Agraria, v. 109, n. 3, p. 303-318, 2013.

RAMSEY, W. S.; HATFIELD, P. G.; WALLACE, J. D. Relationships among ewe milk production and ewe and lamb forage intake in Suffolk and Targhee ewes nursing single or twin lambs. Journal of Animal Science, v. 72, p. 811-816, 1994.

RATTRAY, P. V.; THOMPSON, K. F.; HAWKER, H.; SUMNER, R. M. W. Pastures for sheep production. In: NICOL, A.M. (Ed.). Livestock feeding on pasture. Hamilton: New Zealand Society of Animal Production, p.89-104. 1987.

SILVA, L. F.; PIRES, C. C. Avaliações quantitativas das proporções de osso, músculo e gordura da carcaça em ovinos. Revista Brasileira de Zootecnia, v.29, p.1253-1260, 2000.

SILVA SOBRINHO, A. G.; MACHADO, M. R. F.; GASTALDI, K. A.; GARCIA, C. A. Efeitos da relação volumoso: concentrado e do peso ao abate sobre os componentes da perna de cordeiros lle de France $x$ Ideal confinados. Revista Brasileira de Zootecnia, v. 31, n. 2, 2002.

SILVA SOBRINHO, A. G.; SAÑUDO, C.; OSÓRIO, J. C. S.; ARRIBAS, M. M. C. E OSÓRIO, M. T. M. Produção de carne ovina. Funep. Jaboticabal. 228 p. 2008.

SELAIVE-VILARROEL, A. B.; OSÓRIO, J. C. S. Produção de ovinos no Brasil. Roca. Rio de Janeiro. 656p. 2014. 
TAYLOR, C. S. Use of genetic size scaling in evaluation of animal growth. Journal of Animal Science, v. 61, n. 2, p. 119-141, 1985.

TODARO, M.; CARRAO, A.; BARONE, C. M. A.; SCHINELLI, R.; OCCIDENTE, M. AND GIACCONE, $P$. The influence of age at slaughter and litter size on some quality traits of kid meat. Small Ruminant Research. 2004.

VIANA, J. G. A. Panorama Geral da Ovinocultura no Mundo e no Brasil. Revista Ovinos, v. 4, n. 12, 2008. 